\title{
Lived Experiences of Critically Ill Patients with Covid-19 after Discharge from Intensive Care Unit: A Phenomenological Study
}

\author{
Alireza Nikbakht Nasrabadi ${ }^{1}$, Fatemeh Karami ${ }^{2 *}$, Saeideh Varasteh ${ }^{2}$ and Alireza Arman ${ }^{2}$ \\ 1 Professor, Department of Medical-Surgical Nursing, School of Nursing and Midwifery, Tehran University of Medical Sciences, Tehran, Iran \\ $2 \mathrm{PhD}$ in Nursing, School of Nursing and Midwifery, Tehran University of Medical Sciences, Tehran, Iran
}

* Corresponding author: Fatemeh Karami, School of Nursing and Midwifery, Tehran University of Medical Sciences, Tehran, Iran. Tel: +982161054128; Email: f-karami@razi.tums.ac.ir

Received 2020 January 23; Revised 2021 March 27; Accepted 2021 May 13.

\begin{abstract}
Background: Understanding the experiences of ICU patients with COVID-19 helps to provide the unique care activities, improve the quality of care and promote health status, thereby creating a window for mutual understanding between the treatment team and the patients.

Objectives: The present study aimed to explore lived experiences of critically ill patients with COVID-19 after discharge from intensive care units of hospitals in Iran.

Methods: The present study was qualitative research with a hermeneutic phenomenological approach. Participants were purposefully selected from critically ill patients with COVID-19 who were discharged from the intensive care unit (ICU) and transferred to the general ward. Data were mostly collected through in-depth, semi-structured, face-to-face interviews and, in some cases, telephone calls. Data were analyzed using the method of Dickelman et al. (1985). Guba and Lincoln's (1989) criteria were used to achieve data authenticity.

Results: Data were obtained from 16 COVID-19 recovered patients with a history of ICU admission. Twelve participants were female and four were male with a mean age of 35 years. The four main themes were identified along with their subthemes: perception of death before dying (worry, helplessness, and expecting a different death), social stigma (social isolation and stigma), a nurse as a symbol of rebirth (a compassionate and supportive nurse and the supportive role of others), and meaningful life (a change in outlook on life and the manifestation of spirituality).

Conclusion: The results of the present study indicated that personal thoughts such as thinking about death and social treatments such as stigma can lead to threatening physical and psychological problems in COVID-19 patients. Nurses and family members can prevent many of these problems by providing holistic care and psychological support. Apart from the challenges posed by the disease, post-recovery changes in patients' attitudes toward life can be considered as a positive point.

Keywords: COVID-19, Discharge, Intensive care unit, Lived experience, Phenomenology
\end{abstract}

\section{Background}

World Health Organization (WHO) introduced a new coronavirus strain as the cause of a new respiratory disease called COVID-19 following the announcement of several unusual cases of pneumonia by China in early 2020 (1). Coronaviruses cause different diseases, from the common cold to more severe diseases such as severe acute respiratory syndrome (SARS) and middle east respiratory syndrome (MERS). It should be noted that this newly discovered virus is different from previous types (2). The virus can cause respiratory failure and even death in infected people (3).

Despite the high global prevalence of COVID-19, there is still no definitive treatment $(4,5)$. The unpredictable nature of the disease, rapid spread of the virus, the inadequacy of facilities, and shortage of skilled caregivers have challenged health care systems in most countries around the world (6). Consequently, the disease affected more than 56 million people worldwide, of whom 1350545 have already died. According to the latest global report, COVID-19 has affected 801,894 people and led to the death of 42,941 people in Iran (7).

The disease is asymptomatic or with minor symptoms in most people, which can be managed without hospitalization (8); however, studies have indicated that about 5\% of COVID-19 patients are admitted to ICU (9). The most important reason for ICU admission is the special need to receive respiratory support such as oxygen therapy and mechanical ventilation. The mortality rate of COVID19 among patients in ICU is $31 \%$ (10). Results of a systematic review study, which included 24 studies from different countries, showed that the mortality rate among patients with COVID-19 in ICU is about $41.6 \%$ which is higher than other viral pneumonia (11). According to statistics released by the Ministry of Health and Medical Education in Iran, the number of critically ill patients with COVID-19 in ICU is 5,712 people (12).

ICU admission indicates a traumatic event. According to the literature review, individuals experience a variety of psychological problems, such as post-traumatic stress disorder and cognitive-anxiety disorders after discharge $(13,14)$. These problems can affect the quality of life in many ways (15).

Interviews with people discharged from ICU indicated that although they felt returned to life, they were always struggling with the anxiety of re-infection 
and ICU admission (16). In another study, patients discharged from the ICU ward preferred death to life as they had lost their hope and meaning of life (17).

Factors such as diagnosis, fear of transmitting the virus to relatives, social isolation, and even mortality reports by social media (18) can lead to stress, a feeling of being on the deathbed, anger, and depression among patients with COVID-19 $(19,20)$. ICU admission exacerbates these cases.

ICU admission of COVID-19 patients simultaneously creates unknown and unique experiences due to a combination of critical factors such as having conflicting information through social media, the uncertainty of the disease process, specific ICU environment, and different type of treatment from other wards. Previous studies have shown that most ICU COVID-19 ICU survivors have unique pleasant and unpleasant experiences (21-23). Evidence suggests that delirium is more common among patients with COVID-19 in ICU, which is associated with insecurity and panic (24).

Symptoms such as respiratory distress, general weakness, fatigue, decreased visual acuity, dysfunction, and memory impairment may interminably persist among COVID-19 patients, especially in those who have experienced severe forms of the disease (25). These problems in turn increase the feeling of dependence on others and subsequent psychological damage (26).

There are currently few COVID-19 studies, especially qualitative researches that explore the experiences of patients with COVID-19 in ICU; therefore, careful consideration of patients' experiences is very important. Increasing such understanding helps planning, selecting unique care activities, and implementing appropriate interventions to promote all dimensions of health status. Additionally, using the experiences of the patients can open the door to mutual understanding between nurses and the treatment team to improve the quality of care and accelerate the recovery of these patients.

A phenomenological approach can provide comprehensive information about the lived experiences of recovered ICU patients with COVID-19 admitted to the ICU to explore the meanings and challenges facing them.

\section{Objectives}

This study was conducted to evaluate the experiences of critically ill patients with COVID-19 in Iran after discharge from the ICU and being transferred to the general ward or home.

\section{Methods}

\subsection{Study design}

The present study is qualitative research with a hermeneutic phenomenological approach aimed at understanding the experiences of critically ill COVID19 patients discharged from the ICU.

\subsection{Sample and the sampling method}

Purposeful sampling was performed on critically ill COVID-19 patients discharged from the ICU, after at least one week, when they reached a stable state to communicate properly and provide rich and complete information to the research team.

In this type of sampling, the sample size was not specified in advance and the sampling process continued until the adequacy and richness of the data were achieved. Attempts were made to select participants with diverse characteristics of age, gender, and occupation to maximize diversity and achieve the richness of theoretical information. The exclusion criteria were reluctance to continue the interview for any possible reason. Before the interview, the purpose of the study, the time of the interview, and the procedure of answering the questions were explained to the participants, and informed consent was obtained from them.

\subsection{Data Collection}

Data collection instruments were in-depth individual, face-to-face, and semi-structured interviews. The interview began with general questions and was followed by a pivotal question, "Explain your understanding of COVID-19." Subsequently, some of the following questions were used: "Can you tell us about your COVID-19 experience and the related problems? What were your hopes and needs during the disease? How did you feel about being hospitalized? How did you live with this disease? What was your experience of being admitted to ICU? How was your experience after discharge? What was the difference between this disease and others?". The following probing questions were also used during the interview to clarify information: "What do you mean?", "Could you explain more about this?", "Could you give a clear example of what you mean?"

The duration of each interview varied from 30 to 90 minutes depending on the conditions of the participants. Some interviews were also conducted in two sessions to resolve ambiguity. Data were collected through face-to-face interviews, and in some cases, by telephone calls depending on the choice of the participants. All interviews and conversations were recorded according to the initial coordination.

\subsection{Data analysis}

Dickelman et al.'s (1989) analysis was adopted for data analysis (27). This seven-step method is based on Heideggerian phenomenology as follows:

1. Reading all interviews and texts to obtain a general understanding 
2. Writing interpretive summaries for each interview

3. Analyzing selected versions of texts or interviews in groups, and identifying and extracting themes

4. Referring to the interview transcript to reach an overview of each interview

5. Comparing the interviews to determine common meanings and functions

6. Identifying the basic patterns related to the topics

7. Presenting a draft of the themes to the commentator team and other partners for finalization

Accordingly, the interview transcript was reviewed several times for a general understanding after each interview. Then, an interpretive summary was written for each interview transcript to extract the explicit and implicit meanings. In the meantime, interpretations and themes emerged. The interview transcripts were reviewed or returned to the participants several times to resolve, explain and classify inconsistencies in interpretations. At each stage, interpretive summaries and their combined analyses were integrated to establish appropriate relationships between themes. MAXQDA10 software was used to manage large volumes of data.

\subsection{Data authenticity}

The criteria presented by Guba and Lincoln (1985) were used to achieve authenticity (28). The four criteria of credibility, confirmability, transferability, and dependability were employed. To this end, efforts were made to ensure reliability and validity of the study findings by selecting an appropriate context and eligible participants, correcting information sources, immersing into deep data through prolonged engagement, engaging subjects in the interpretation process, using the general opinions of the research team and experts who were familiar with the studied phenomenon.

\subsection{Ethical Considerations}

The present study is approved by the Ethics Committee of Tehran University of Medical Sciences, Tehran, Iran (IR.TUMS.VCR.REC.1399.163) (29). Informed consent was obtained from all participants while emphasizing the confidentiality of information as well as anonymity.

\section{Results}

A total of 19 interviews sessions were analyzed. Sixteen people participated in the study, including 12 women and 4 men with a mean age of 35 years. Thirteen were married and 12 had a bachelor's degree or higher. The mean ICU length of stay was 7 days.

Finally, 4 main themes and 9 sub-themes were extracted through the analysis of the experiences of critically ill patients admitted to the ICU, which include perception of death before dying, social stigma, nurse as a symbol of rebirth, and meaningful life. Each of the main themes consists of sub-themes listed in Table 1 . In the following, these cases are presented while using direct quotations from patients.

\subsection{Perception of death before dying}

This main theme includes the sub-themes of worry, helplessness, and expecting a different death. Participants experienced severe psychological conditions due to COVID-19. Fears related to the unknown aspects of the disease, instantaneous change of status, and lack of hope for defeating the

\begin{tabular}{|c|c|c|}
\hline Main themes & Sub-themes & Meaning units \\
\hline \multirow{3}{*}{ Perception of death before dying } & Worry & $\begin{array}{c}\text { Fear of transmitting the disease to others, infecting the family, not } \\
\text { being alive, false fear, fear of the unknown, financing, worrying } \\
\text { about the future after the disease }\end{array}$ \\
\hline & Helplessness & $\begin{array}{c}\text { Ennui, depression, feeling stuck in daily routines, stopping time, } \\
\text { troubled conscience, hatred, feeling of being a burden on } \\
\text { somebody, complications of the disease, feeling helpless, } \\
\text { frustration with recovery, confusion }\end{array}$ \\
\hline & Expect a different death & $\begin{array}{l}\text { Thinking about death, painful death, the unpleasant experience of } \\
\text { the death of others, the feeling of imminent death, the observation } \\
\text { of death, the end of life of other family members after death, the } \\
\text { loss of loved ones, lonely death, waiting for death }\end{array}$ \\
\hline \multirow{2}{*}{ Social stigma } & Social isolation & Social isolation, being rejected, deprivation, loneliness \\
\hline & Stigma & Negative attitude, label someone as inconsiderate, blame \\
\hline \multirow[t]{2}{*}{ A nurse as a symbol of rebirth } & $\begin{array}{l}\text { A compassionate and } \\
\text { supportive nurse }\end{array}$ & $\begin{array}{c}\text { Presence, meaningful communication, non-discrimination, } \\
\text { compassion, assurance of recovery, continuous, steady, and solid } \\
\text { effort }\end{array}$ \\
\hline & The supportive role of others & Supporter, motivation to survive, consolation, patience \\
\hline \multirow[t]{2}{*}{ Meaningful life } & A change in attitude to life & $\begin{array}{c}\text { Past regrets, the need for compensation, positive thinking, reusing } \\
\text { the opportunity, paying special attention to health, valuing life, } \\
\text { reducing fears, maintaining morale }\end{array}$ \\
\hline & Manifestation of spirituality & Seeking spiritual support, religious beliefs \\
\hline
\end{tabular}


disease, induced feelings of overwhelming helplessness and disability. The prevalence of disease affected some patients so that they wanted to end their lives. This feeling of helplessness was not limited to the time of the disease but also persisted after recovery. The anxiety of re-infection, and the thought of re-experiencing the difficult conditions of the disease had left some people frustrated and unmotivated to continue living.

Patients expressed a variety of reasons for their anxiety and fear. From the perspective of these patients, COVID-19 was a life-threatening disease that affected all aspects of their lives, and the fear of the unknown aspects of the disease gave them a vision of an unknown future. Most stated that although they were in poor physical conditions at the time of hospitalization and thereafter, their greatest concern was transmitting the disease to family members. They blamed themselves for the slightest symptoms in their relatives.

"My sister called me that she has these symptoms... I forgot my disease. God, what if she is infected? I will not forgive myself... (P7)".

Although people were in a state of recovery at the time of the interview, some were anxious for reinfection. Some participants had to see a psychologist to overcome this stress and return to daily life.

"I'm scared to get it again because my lungs are weak... (P4)".

The time of hospitalization in ICU triggered posttraumatic stress disorder in some patients.

"When I saw a large number of devices, my fear and panic increased a hundredfold. I had completely lost myself .... I still feel hopelessness and scared remembering those days (P6)".

Other issues related to the disease include concerns for hospital bills, job losses, and family finances.

"I am an employee and my biggest concern was that I could not take much leave from work... I might lose my job because of this disease (P14)".

The disease was accompanied by a variety of emotional manifestations. These problems ranged from diagnosis to recovery. The complexity of the nature of the disease had left them a sense of hopelessness about recovery as well as mental distress.

"Chaotic heart, certain anxiety, an incomprehensible feeling in my brain... What was this disease? Where did it come from? What is this? What should we do? ... (P5).

"I had no hope of being discharged from the ICU ... because there were many critically ill patients around me that greatly affected my mood...No one should come to visit me. My family could not visit us; it was very annoying to be alone (P14)."

"I missed my children very much ... It was the hardest torment ... I was telling God all my pain and asked him to help me endure it for the sake of my children and get well as soon as possible (P6)."
The thought of death is one of the concepts that all patients encountered. Participants stated that unknown dimensions of the disease, unpredictable mortality rate, the critical physical conditions leading to ICU admission. Death of other people who were hospitalized at the same time, and the different ways of burying occupied their minds. These people were afraid of dying alone. furthermore, thinking about the lives of other family members in their absence had raised concerns.

"I remember the time when I opened my eyes in the ICU, I was looking to my right side. Many beds were occupied by motionless patients... I felt I was getting closer to death (P11). "

"... For example, if I died, it would be humiliating ... I proudly lived for 46 years, then they could not even hold a burial ceremony for me... (P12)"

"At that time, I decided to call those I had problems with and ask them for reconciliation... However, some nights I wished to die..., I was ready to die just to end this situation (P11)."

\subsection{Social stigma}

The participants were involved with the social stigma of the disease and subsequent isolation. Labeling and abandonment by society or even relatives had caused great psychological suffering to individuals. Some participants claimed that the fear of being stigmatized by others was the main cause of delayed referral to the hospital to receive special care, disease progression, and hospitalization in the ICU. Stigma caused them to hide the disease for a long time so that they missed the opportunity for treatment. This problem was especially common among those who were the first members to be infected in relatives. In addition, misconceptions and the stigma made the acceptance of the disease impossible for the person and others in some cases which provide conditions for greater vulnerability.

"When my quarantine ended, my parents did not accept me despite being educated... Also, other people were very scared, for example, because I was infected... one of our neighbors went to another city for exactly one month ... (P8). "

"My family had a negative attitude towards this disease, and they thought that anyone who gets COVID-19 is a person who does not observe health protocols, especially me that I was admitted to the ICU." (P6).

\subsection{A nurse as a symbol of rebirth}

According to the recovered patients, the role of nurses and families cannot be ignored during the transition from the disease stage and the subsequent period. In their view, nurses were at the forefront of the fight against COVID-19. They tried to cure all the patients by implementing specialized care. Participants stated that nurses maintained their morale and provided psychological support to 
patients despite working in difficult conditions.

Additionally, the support of family members played a vital role in improving the emotional state and maintaining the spirit to fight the disease. The participants stated that the active presence of family members and their regular care accelerated the recovery process and compensated for psychological harms caused by disease after returning home. Participants believed that only family members supported them under the most difficult circumstances, which strengthened their sense of worth.

"... Although the number of patients was high, the nurses gave medications on time... It was only with the care of the nurses that we got better day by day and our hope for being alive was increased... They didn't postpone other care services. (P14) "

"One night, one of the male nurses came to sit next to me ... He said: tell me about yourself and your life... I felt much better that night, and helped me release annoying thoughts (P11)."

"My wife came and sat next to me, she was very supportive and did not let me be emotionally disturbed. She provided me with everything I asked for. It was a pleasant feeling when my family understood me ..." (P13).

\subsection{Meaningful life}

Participants believed that they were given a second chance for life and they had to choose the right path. They believed that being admitted to ICU and rescuing from COVID-19 was one of the most effective periods of their life which learn them to seize the moment. They also stated that their perspective towards life changed after the recovery. These people tried to compensate for the missed opportunities while taking the advantage of a positive attitude.

Furthermore, this disease encouraged people to observe health protocols. They believed that they need to put aside fears and maintain their morale under unpredictable situations. Individuals often use spirituality under difficult situations to overcome mental problems. Some participants stated that suffering from Covid-19 and the resulting loneliness caused them to feel the presence of God and other spiritual forces in their lives more than ever.

"It was one of the most influential periods in my life, my attitude toward life completely changed ...If I have a backlog, I should do it sooner... My maturity seems to have increased (P11)."

"I have to seize the day...I need to know the value of my possessions otherwise, it becomes an unattainable dream (P6)."

" The moment I woke up from the coma, the nurse came to the bed to tell me what happened. I said I saw Zaynab bint Ali ... a woman who is tall but I could not see her face ... I said hold my hand to get up ... As soon as she took my hand, everything was over and I gained my consciousness (P4)".

\section{Discussion}

The present study aimed to investigate the lived experiences of critically ill COVID-19 patients after discharge from ICU in Iran. The main themes obtained from the statements of participants included perception of death before dying, social stigma, a nurse as a symbol of rebirth, and meaningful life.

The first main theme identified in the present study was the perception of death which consisted of the sub-themes of worry, helplessness, and expecting a different death. Having COVID-19 disease and being admitted to the ICU is a stressful experience for people. In the present study, it was found that all participants experienced different worries and fears. They experienced emotional and behavioral reactions such as fear, anxiety, depression, impatience, hatred, frustration, and confusion. These findings are consistent with the results of the study by Shigemura et al. (2020), which aimed to examine general responses to the coronavirus (30). Sahoo et al. (2020) also found that $38 \%$ of patients with COVID-19 suffer from anxiety disorders and depression caused by the disease (31). The main cause of fear is family members being infected and the anxiety caused by the unknown. Other factors include anxiety about the future after disease, re-infection, COVID-19 news, and costs.

The experience of quarantine and loneliness was painful for the patients since family relationships are so important in Iran. Guo et al. (2020) also investigated 103 patients with COVID-19 and found that they had multiple psychological disorders due to quarantine (19), which requires appropriate psychological-supportive interventions along with physical therapy.

Overall, any event that induces end-of-life conditions for individuals is associated with death anxiety and psychological trauma (32). As in the present study, patients frequently thought of death especially those who witnessed the death of other patients in the ICU. The image of death for oneself and others, and the special burial of the deceased caused them to lose their morale and feel the imminent death. Furthermore, concerns about the future of family members after death intensified the feeling of anxiety. Therefore, reducing the anxiety of thinking about death and psychological disturbances in the case of COVID-19 is an important aspect of care like other fatal diseases (33).

Other themes in this study are social isolation and stigma. Social stigma is a phenomenon often associated with discrimination and deprivation, which leads to detrimental effects on mental health, and feelings of rejection and isolation (34). The patients in the present study stated that they experienced social stigma and rejection by their 
relatives after discharge from ICU. This made it difficult for many patients to return to work. A study also indicated that a consequence of stigma related to COVID-19 is a loss of productivity and income from work (35). From the participants' point of view, dealing with the negative attitude of others, and being blamed by society is difficult. A report during the Covid-19 epidemic shows that suspected people were not allowed to leave their homes or travel to public places such as shops even after the quarantine period was over (36). It should be noted that people who experience stigma and feelings of infamy may hide their disease, which consequently spreads the disease. Therefore, providing accurate information is necessary to stop the stigma $(37,38)$.

A nurse as a symbol of rebirth was another theme identified in the present study. Participants stated that the presence, meaningful communication, compassion, effort, and reassurance by the nurses alleviated psychological distress during ICU admission and isolation. The experiences of the participants show that nurses play an effective role in helping patients in ICU to overcome critical mental conditions through comprehensive nursing interventions because they are in direct contact with the patients. These findings are consistent with the results of the study by Egerod et al. (2015) which showed that nurses and family members have a major role in the process of returning to daily life (39). Social support provided by nurses in the absence of family members can satisfy the fundamental need for communication. Therefore, training the nurses to communicate effectively and safely with COVID-19 patients is necessary.

Family support is a basic need for patients during the disease process until recovery in Iranian culture. The importance of this issue in improving the physical and emotional conditions at the time of infection, hospitalization, and recovery was also mentioned by the participants. However, the comprehensive presence of family members was limited due to precautions during the COVID-19 pandemic, participants stated that receiving family support was a key factor in maintaining their morale to fight the disease.

In general, the family is considered to be a supporter for patients in ICU, and family members are allowed to visit the patient from a few minutes to a few hours a day. However, they are not permitted to visit their patients hospitalized in ICU due to the COVID-19 exposure risk, which increases the feeling of loneliness, fear, and psychological trauma in patients (31). The supportive role of the family for patients with COVID-19, especially for those hospitalized in the ICU, is notably marginalized under these conditions (40), while the emotional and supportive role of the family needs to be sustained (41). For this purpose, alternative methods should be used to implement the family role. Applying new family-centered care approaches such as using cyberspace maintains communication between the patient and family members and provides highquality moral, psychological, and social care from the family in current condition (42).

Another theme identified in this study was a meaningful life, which consists of two sub-themes of change in life perspective and the manifestation of spirituality. Results of a study revealed that hospitalization in ICU left lasting effects on people's lives after discharge (43). The findings of the present study also indicated surviving the challenging disease changed participants' view of life. These people were reported to lead more efficient lives, particularly for welfare and health promotion.

Patients in ICU stated that spirituality is important (44) and resorting to supernatural power is effective in reducing distress in critical situations (45). Hospitalization in ICU led the participants to improve their physical, emotional, and spiritual condition. ICU nurses must learn spiritual care due to the high mortality rate in patients with Covid-19 and considering the conditions of the ICU where the patient feels imminent death (46). Furthermore, religious beliefs and spirituality can induce a sense of hope for the future, and also accelerate the recovery of patients.

\section{Conclusion}

The results of the present study indicated that patients with COVID-19 and a history of ICU admission experience a variety of problems. Unpleasant experiences related to the disease can lead to emotional responses along with feelings of helplessness and failure. Going through a critical period in the ICU and observing others die of a common disease can induce thinking about an early death. Moreover, lack of timely follow-up to receive health care as a result of stigma can lead to threatening physical conditions, prolonging the treatment process, and causing mental problems after discharge.

The role of nurses and families cannot be ignored in maintaining the morale of patients to fight the disease. Therefore, these patients need more psychological support and comprehensive care from nurses, family, and community.

Although COVID-19 challenges the survival of the patients, it also affects the patient to improve their welfare and health. Therefore, understanding the experience of these patients can provide a suitable framework for identifying their needs to take effective action for accelerating the treatment process through planning appropriate interventions.

\section{Acknowledgments}

The present study was financially supported by 
the Vice-Chancellor for Research and Technology, Tehran University of Medical Sciences, Tehran, Iran. Hereby, the authors would like to express their sincere gratitude to all participants in this study.

\section{Footnotes}

Conflicts of Interest: The authors declare that there is no conflict of interest regarding the publication of the present study.

\section{References}

1. World Health Organization. Novel coronavirus-China. Geneva: World Health Organization; 2020.

2. Wu C, Chen X, Cai Y, Zhou X, Xu S, Huang H, et al. Risk factors associated with acute respiratory distress syndrome and death in patients with coronavirus disease 2019 pneumonia in Wuhan, China. JAMA Intern Med. 2020;180(7):934-43. doi: 10.1001/jamainternmed.2020.0994. [PubMed: 32167524].

3. Zhu N, Zhang D, Wang W, Li X, Yang B, Song J, et al. A novel coronavirus from patients with pneumonia in China, 2019. N Engl J Med. 2020;382(8):727-33. doi: 10.1056/NEJMoa2001017. [PubMed: 31978945].

4. Shrivastava SR, Shrivastava PS. Minimizing the risk of international spread of coronavirus disease 2019 (COVID-19) outbreak by targeting travelers. J Acute Dis. 2020;9(2):47. doi: 10.4103/2221-6189.278654.

5. Bogoch II, Watts A, Thomas-Bachli A, Huber C, Kraemer MU, Khan K. Potential for global spread of a novel coronavirus from China. J Travel Med. 2020;27(2):taaa011. doi: 10.1093/jtm/taaa011. [PubMed: 31985790].

6. Emanuel EJ, Persad G, Upshur R, Thome B, Parker M, Glickman $A$, et al. Fair allocation of scarce medical resources in the time of Covid-19. N Engl J Med. 2020;382(21):2049-55. doi: 10.1056/NEJMsb2005114. [PubMed: 32202722].

7. World Health Organization. Coronavirus disease (COVID-19) situation report-202. Geneva: World Health Organization; 2020.

8. Struyf T, Deeks JJ, Dinnes J, Takwoingi Y, Davenport C, Leeflang MM, et al. Signs and symptoms to determine if a patient presenting in primary care or hospital outpatient settings has COVID-19 disease. Cochrane Database Syst Rev. 2020; 7(7):CD013665. doi: 10.1002/14651858.CD013665. [PubMed: 32633856].

9. Guan WJ, Ni ZY, Hu Y, Liang WH, Ou CQ, He JX, et al. Clinical characteristics of coronavirus disease 2019 in China. N Engl J Med. 2020;382(18):1708-20. doi: 10.1056/NEJMoa2002032.

10. Abate SM, Ahmed Ali S, Mantfardo B, Basu B. Rate of Intensive Care Unit admission and outcomes among patients with coronavirus: a systematic review and Meta-analysis. PloS One. 2020;15(7):e0235653. doi: 10.1371/journal.pone.0235653. [PubMed: 32649661].

11. Armstrong R, Kane A, Cook T. Outcomes from intensive care in patients with COVID-19: a systematic review and meta-analysis of observational studies. Anaesthesia. 2020;75(10):1340-9. doi: 10.1111/anae.15201. [PubMed: 32602561].

12. Ministry of Health and Medical Education. Available at: URL: https://behdasht.gov.ir/; 2021.

13. Davydow DS. The burden of adverse mental health outcomes in critical illness survivors. Crit Care. 2010;14(1):125. doi: 10.1186/cc8867. [PubMed: 20236473].

14. Kiekkas P, Aretha D. Psychiatric long-term complications of intensive care unit survivors. Crit Care Med. 2011;39(7):1852-3. doi: 10.1097/CCM.0b013e318218546c. [PubMed: 21685763].

15. Granja C, Lopes A, Moreira S, Dias C, Costa-Pereira A, Carneiro A. Patients' recollections of experiences in the intensive care unit may affect their quality of life. Crit Care. 2005;9(2):R96109. doi: 10.1186/cc3026. [PubMed: 15774056].

16. Abdalrahim MS, Zeilani RS. Jordanian survivors' experiences of recovery from critical illness: a qualitative study. Int Nurs Rev. 2014;61(4):570-7. doi: 10.1111/inr.12142. [PubMed: 25382166].

17. Corrigan I, Samuelson KA, Fridlund B, Thomé B. The meaning of posttraumatic stress-reactions following critical illness or injury and intensive care treatment. Intensive Crit Care Nurs. 2007;23(4):206-15. doi: 10.1016/j.iccn.2007.01.004. [PubMed: 17449252].

18. Xiang YT, Yang Y, Li W, Zhang L, Zhang Q, Cheung T, et al. Timely mental health care for the 2019 novel coronavirus outbreak is urgently needed. Lancet Psychiatry. 2020; 7(3):228-9. doi: 10.1016/S2215-0366(20)30046-8. [PubMed: 32032543].

19. Guo Q, Zheng $Y$, Shi J, Wang J, Li G, Li C, et al. Immediate psychological distress in quarantined patients with COVID-19 and its association with peripheral inflammation: a mixedmethod study. Brain Behav Immun. 2020;88:17-27. doi: 10.1016/j.bbi.2020.05.038. [PubMed: 32416290].

20. Huang Y, Zhao N. Generalized anxiety disorder, depressive symptoms and sleep quality during COVID-19 outbreak in China: a web-based cross-sectional survey. Psychiatry Res. 2020;288:112954. doi: 10.1016/j.psychres.2020.112954. [PubMed: 32325383].

21. Samuelson KA. Unpleasant and pleasant memories of intensive care in adult mechanically ventilated patients--findings from 250 interviews. Intensive Crit Care Nurs. 2011;27(2):76-84. doi: 10.1016/j.iccn.2011.01.003. [PubMed: 21371888].

22. Jeong YJ, Kang J. Development and validation of a questionnaire to measure post-intensive care syndrome. Intensive Crit Care Nurs. 2019;55:102756. doi: 10.1016/j. iccn.2019.102756. [PubMed: 31522829].

23. Barreto BB, Luz M, de Oliveira Rios MN, Lopes AA, GusmaoFlores D. The impact of intensive care unit diaries on patients' and relatives' outcomes: a systematic review and metaanalysis. Crit Care. 2019;23(1):411. doi: 10.1186/s13054-0192678-0. [PubMed: 31842929].

24. Tandon R. The COVID-19 pandemic, personal reflections on editorial responsibility. Asian J Psychiatr. 2020;50:102100. doi: 10.1016/j.ajp.2020.102100. [PubMed: 32354694].

25. Sheehy LM. Considerations for postacute rehabilitation for survivors of COVID-19. JMIR Public Health Surveill. 2020;6(2):e19462. doi: 10.2196/19462. [PubMed: 32369030].

26. Jaffri A, Jaffri UA. Post-Intensive care syndrome and COVID-19: crisis after a crisis? Heart Lung. 2020;49(6):883-4. doi: 10.1016/j.hrtlng.2020.06.006. [PubMed: 32690219].

27. Diekelmann NL, Allen D, Tanner CA. The NLN criteria for appraisal of baccalaureate programs : a critical hermeneutic analysis. New York: National League for Nursing; 1989.

28. Lincoln YS, Guba EG. Naturalistic Inquiry. Newbury Park, CA: Sage; 1985.

29. Nasrabadi AN. Lived Experiences of Iranian ICU Nurses in the care of patients with Covid-19: a phenomenological study. Res Square. 2020;In Pess. doi: 10.21203/rs.3.rs-72171/v1.

30. Shigemura J, Ursano RJ, Morganstein JC, Kurosawa M, Benedek DM. Public responses to the novel 2019 coronavirus (2019-nCoV) in Japan: mental health consequences and target populations. Psychiatry Clin Neurosci. 2020;74(4):281-2. doi: 10.1111/pcn.12988. [PubMed: 32034840].

31. Sahoo S, Mehra A, Dua D, Suri V, Malhotra P, Yaddanapudi LN, et al. Psychological experience of patients admitted with SARSCoV-2 infection. Asian J Psychiatry. 2020;54:102355. doi: 10.1016/j.ajp.2020.102355. [PubMed: 33271684].

32. Lagerdahl AS, Moynihan M, Stollery B. An exploration of the existential experiences of patients following curative treatment for cancer: reflections from a UK sample. J Psychosoc Oncol. 2014;32(5):555-75. doi: 10.1080/07347332.2014.936647. [PubMed: 25045924].

33. Lo C, Hales S, Jung J, Chiu A, Panday T, Rydall A, et al. Managing cancer and living meaningfully (CALM): phase 2 trial of a brief individual psychotherapy for patients with advanced cancer. Palliat Med. 2014;28(3):234-42. doi: 10.1177/0269216313507757. [PubMed: 24170718].

34. Jang J, Lee SA, Kim W, Choi Y, Park EC. Factors associated with mental health consultation in South Korea. BMC Psychiatry. 
2018;18(1):17. doi: 10.1186/s12888-018-1592-3. [PubMed: 29357835].

35. Li W, Yang Y, Ng CH, Zhang L, Zhang Q, Cheung T, et al. Global imperative to combat stigma associated with the coronavirus disease 2019 pandemic. Psychol Med. 2020;26:1-2. doi: 10.1017/S0033291720001993. [PubMed: 32450925].

36. Peprah P, Gyasi RM. Stigma and COVID-19 crisis: a wake-up call. Int J Health Plann Manage. 2020;36(1):215-8. doi: 10.1002/hpm.3065. [PubMed: 32845533].

37. Rahmatinejad P, Yazdi M, Khosravi Z, Shahisadrabadi F. Lived experience of patients with coronavirus (Covid-19): a phenomenological study. J Res Psychol Health. 2020; 14(1):71-86.

38. Stop the coronavirus stigma now. Nature. 2020;580(7802):165. doi: 10.1038/d41586-020-01009-0. [PubMed: 32265571].

39. Egerod I, Bergbom I, Lindahl B, Henricson M, Granberg-Axell A, Storli SL. The patient experience of intensive care: a metasynthesis of Nordic studies. Int J Nurs Stud. 2015;52(8):135461. doi: 10.1016/j.ijnurstu.2015.04.017. [PubMed: 25986960].

40. Wendel PK, Stack RJ, Chisholm MF, Kelly MJ, Elogoodin B, Liguori GA, et al. Development of a communications program to support care of critically ill coronavirus disease 2019 (COVID-19) patients. J Patient Exp. 2020;7(5):673-676. doi: 10.1177/2374373520956865. [PubMed: 33294597].

41. Gaulton J, Ziegler K, Chang E. Virtual practices transform the care delivery model in an intensive care unit during the coronavirus pandemic. Nejm Catalyst Innovat Care Deliv. 2020; In Press.

42. da Silva Ribeiro CA, Trovo MM, Puggina AC. Life stories and photographs of sedated patients in the ICU: a possible humanization strategy? Enferm Glob. 2017;16(3):483-95. doi: 10.6018/eglobal.16.3.257291.

43. Storli SL, Lindseth A, Asplund K. A journey in quest of meaning: a hermeneutic-phenomenological study on living with memories from intensive care. Nurs Crit Care. 2008;13(2): 86-96. doi: 10.1111/j.1478-5153.2007.00235.x. [PubMed: 18289187].

44. Aslakson RA, Kweku J, Kinnison M, Singh S, Crowe TY 2nd, Ast K, et al. Operationalizing the measuring what matters spirituality quality metric in a population of hospitalized, critically ill patients and their family members. J Pain Symptom Manage. 2017;53(3):650-5. doi: 10.1016/j.jpainsymman.2016.12.323. [PubMed: 28042059].

45. Weber SR, Pargament KI. The role of religion and spirituality in mental health. Curr Opin Psychiatry. 2014;27(5):358-63. doi: 10.1097/YCO.0000000000000080. [PubMed: 25046080].

46. Noome M, Beneken Genaamd Kolmer DM, van Leeuwen E, Dijkstra BM, Vloet LC. The role of ICU nurses in the spiritual aspects of end-of-life care in the ICU: an explorative study. Scand J Caring Sci. 2017;31(3):569-78. doi: 10.1111/scs.12371. [PubMed: 27862140]. 